\title{
The Relationship Between Cultural Diversity and User Needs in Virtual Reference Services
}

by Pnina Shachaf and Mary Snyder

\author{
Pnina Shachaf, School of Library and Information Science, \\ Indiana University, 1320 E. 10th St., LI005A, \\ Bloomington, IN 47405-3907, USA \\ shachaf@indiana.edu; \\ Mary Snyder, Snowden Library, \\ Lycoming College, 700 College Place, \\ Williamsport, PA 17701, USA \\ snyderm@lycoming.edu.
}

While the racial diversity of academic library users continues to grow, research on the effects of this diversity remains scarce. This study looks at similarities and differences between non-traditional Caucasian and African American library users through content analysis of ninety-four virtual reference transactions.

\section{INTRODUCTION AND BACKGROUND}

According to the 2004 US Census, 67 percent of the American population was Caucasian (nonHispanic), 12 percent was Black or African American, 4 percent was Asian, and 14 percent was Hispanic (people of Hispanic origin may be of any race) .1 These diverse groups are making growing use of the Internet; 73 percent of Caucasians (non-Hispanic), 79 percent of (Englishspeaking) Hispanics, and 60 percent of African Americans (non-Hispanic) are using the Internet. 2 These diverse user groups are making growing use of library services. More of them are attending colleges 3 and participating in distance education programs.4 They are also using remote library services, such as virtual reference.

While diverse user groups are making use of academic library services today more than ever, research into the effect of cultural diversity on information seeking behavior is scarce. Studies have addressed diversity of education level, gender, country of origin, and ethnic background of library users. For example, Barbara Valentine focused on research behavior of undergraduates. Ethelene Whitmire's longitudinal study follows the changes in undergraduates' library usage during their college years.5 Tracy A. Burdick in "'Success and Diversity in Information Seeking: Gender and the Information Search Styles Model," looks at different information search styles among genders. Mengxiong Liu and Bernice Redfern in their article "Information Seeking Behavior of Multicultural Students" as well as Lucinda R. Zoe and Diane DiMartino in "Cultural Diversity and End-User Searching,"” discuss how international students are facing more difficulties in using library resources. Ethelene Whitmire examined the influence of cultural diversity of undergraduates on their library use pattern and reports that students of color used the academic library at higher rates than White undergraduates.6 These studies focused attention on the effect of students' heterogeneity on information seeking behavior, research skills, library usage, and library anxiety. Furthermore, the tendency to ask for help differed among culturally diverse user groups. East Asian students requested more assistance in searching 
databases than native English speakers and female students were more likely to ask for help than males.7

The limited number of studies that have looked at the relationship between race and library use is stunning. However, racial differences in academic performance between African Americans and Caucasians at different educational levels have been reported extensively in the literature.8 One can therefore assume that information needs may differ among ethnic groups. A better understanding of diverse users needs in the library context may shed some light on differences in academic achievements among racial groups.

Most academic libraries today provide virtual services to their students, faculty, and staff.9 At least 83 percent of academic libraries in the US are providing some sort of digital reference according to Joe Janes, and Steve Coffman claims that there are very few libraries today that do not provide at least the minimal level of digital reference service via e-mail.10 It was suggested that the provision of online reference services enables users, who are uncomfortable approaching a librarian in person, to submit anonymous questions to a virtual reference service.11 Similarly, there are certain user groups that cannot come to the library due to physical disabilities, scheduling constraints, or geographical distance and may use 24/7 virtual reference service to overcome these challenges. These users may also find the virtual reference to be more accessible for their needs as it provides services to users anytime, anyplace.12 Virtual reference services are instrumental in providing library support for distance education students.13 While "virtual reference'” normally refers to both e-mail and chat services, the current study focuses on e-mail.

Despite the fact that more services are provided online and more remote and diverse users are making use of these services, researchers have not focused attention on the relationship between cultural diversity and user needs in virtual reference. This paper aims to address this research gap and to explore the differences and similarities in information seeking behaviors of culturally diverse students using remote reference services. Particularly this paper focuses on the use of remote reference services by African American and Caucasian distance education students.

\section{METHODOLOGY}

This study aims to identify the similarities and differences among African Americans and Caucasians by conducting content analysis of ninety-four reference transactions. Using a convenience sampling method, the data originated from requests that were sent to a reference desk by distance education students. The university has only a virtual library with no physical holdings and the reference services are provided by telephone and e-mail from a single office. The university has a total enrollment of more than 20,000 graduate students. The student body is particularly racially diverse and includes 8.9 percent self-declared African American (nonHispanic) and 4.3 percent Hispanic. It is important to note that these numbers are not representative of the true percentages as 37.7 percent of the student body chose not to provide information on their racial background. The students are predominately female (76.3 percent) and have an overall average age of 37.4 years. While there are other differences in user demographics which may influence information-seeking behavior, such as first language, experience with technology, and income level or class, these differences were not documented or examined as part of this study. 


\section{Data Collection}

Selection of reference transactions from the archive for this study involved transactions that were processed by the librarians during four months, from June 2005 to September 2005. The library maintains an archive of all the reference transactions that are asked by phone or by e-mail. Phone transactions are summarized and put into e-mail format. All email transactions are organized in students' folders and are kept in an archive. Transactions that filled the following criteria were included in the study:

1. Ethnic background of the student was specified in the university's student database and was either Black (non-Hispanic) or White.14

2. Transaction included information sent by e-mail directly from the student (not just summaries of phone calls).

3. Only one transaction from each student was selected.

It should be explained here that a transaction may have taken place over a period of time and may have multiple, unrelated needs that were addressed.15 To enable statistical analysis of differences among the two user groups using cross tabulation, we aimed to sample 100 transactions, 50 from each group. This required a screening process of nearly 1700 transactions from the archive. After ensuring that all duplicates were removed, all identifying information was carefully removed from the transactions and ninety-four transactions were included in the analysis. Forty-seven transactions that were sent by Caucasian students and forty-seven by African American students that fit the above criteria. An Excel spreadsheet was created with the demographic information for each student and a numerical code that corresponded with the transaction file.

Users' demographics were evaluated to determine if differences other than ethnicity exist between the two user groups. The two user groups were similar in age and gender distribution. However, both group average ages are different than the average age of graduate students in this university, which is thirty-six. The average age of African American students was 47.5 years and the average age of Caucasian students was 48.5 years. An independent-samples t-test was conducted to evaluate if age of African American and Caucasian users differs. The test was not significant, $\mathrm{t}(92)=.465, \mathrm{p}=.64$. There was no significant difference in the average age of users from the two groups.

\section{Data Analysis}

The unit of analysis was an individual reference transaction. Content analysis of the transaction was conducted to determine similarities and differences between the two user groups. Specifically three areas of interest were the focus of the analysis. First, the number of messages that were sent between the user and the librarian in each transaction, the replies to the follow-up messages, and the number of questions that were submitted in subsequent messages that the user sent were counted. Second, the types of questions that the users asked in the transaction were identified. Each transaction could include multiple questions of various types. Third, the writing style of the user was coded. The coding scheme that was used for content analysis of the transaction is provided in the Appendix. 
Once all transactions were coded by one of the co-authors, the other co-author, coded 10 percent of the transactions to calculate inter-coder reliability (number of agreement divided by the total number of agreements and disagreements). Intercoder reliability was high at 95 percent. While coding, the coders did not refer to the demographic spreadsheet so as not to bias their results. Only after the coding was completed was it entered into the same spreadsheet to compare with the demographic data.

\section{FINDINGS}

Table 1 reports the frequencies of codes that were found for each user group. While some variations exist between the two user groups in most cases these differences are small.

As can be seen in Table 1, on average African American users sent 10.5 messages and Caucasian users sent 7.5 messages. An independent-samples t-test was conducted to evaluate if the number of messages sent by African American and Caucasian users significantly differs. The test was not significant, $\mathrm{t}(92)=1.102, \mathrm{p}=.27$.

In order to evaluate whether the frequencies of codes significantly differ between the two user groups, cross tabulation was conducted. The results of the cross tabulation analysis are provided in Table 2. For each of the codes that had at least five cases per cell, a two-way contingency table analysis was conducted to evaluate whether the frequencies of codes by users were significantly different among the two ethnic groups.

As can be seen in Table 2, African Americans were more likely to ask for more help in response to a follow-up, Pearson v2 $(1, \mathrm{~N}=94)=5.5, \mathrm{p}=.01$, Cramer's $\mathrm{V}=.24$. They asked additional questions in the second message more than Caucasian students. Other significant differences ( $\mathrm{p}$ N.05) were found in the type of questions sent by students from each of the two user groups. A significant relationship was found between technical questions and ethnic groups, Pearson v2 (1, $\mathrm{N}=94)=5.3, \mathrm{p}=.02$, Cramer's $\mathrm{V}=.238$. Caucasian students asked more technical questions than African American students. Topical questions and ethnic group were found to be significantly related, Pearson v2 (1, N =94)=2.54, $\mathrm{p}=.1$, Cramer's V =.165. African American students asked more topical questions than Caucasian students. Known item and the two ethnic group were found to be significantly related, Pearson v2 (1, $\mathrm{N}=94)=2.01, \mathrm{p}=.1$, Cramer's V =.146. African American students asked more known item questions than Caucasian students. Similarly, significant differences between the two user groups (N.1) were found for grammatical errors. African American students were more likely to have grammatical errors in their messages Pearson v2 (1, N =94)=3.2, p =.1, Cramer's V =.18. 


\begin{tabular}{|c|c|c|c|}
\hline \multicolumn{4}{|c|}{$\begin{array}{c}\text { Table } 1 \\
\text { Frequencies of Codes Per User Group }\end{array}$} \\
\hline Frequencies & & African American & Caucasian \\
\hline \multirow[t]{12}{*}{ Style } & Greetings & 26 & 24 \\
\hline & Closure & 37 & 33 \\
\hline & Elaborate & 11 & 9 \\
\hline & Exact & 30 & 31 \\
\hline & Succinct & 7 & 7 \\
\hline & Context-irrelevant & 5 & 7 \\
\hline & Purpose & 8 & 9 \\
\hline & Misspelled & 1 & 2 \\
\hline & Typos & 7 & 6 \\
\hline & Grammatical & 13 & 6 \\
\hline & Apologies & 4 & 3 \\
\hline & Excessive gratitude & 5 & 1 \\
\hline \multirow[t]{7}{*}{ Type of question } & Topical & 17 & 10 \\
\hline & Known item & 15 & 9 \\
\hline & Technical & 14 & 25 \\
\hline & Searching instruction & 4 & 3 \\
\hline & Citation & 4 & 2 \\
\hline & Verification & 1 & 1 \\
\hline & Non-reference & 7 & 8 \\
\hline \multirow[t]{3}{*}{ Number of questions } & First & 44 & 46 \\
\hline & Second & 23 & 14 \\
\hline & Third & 9 & 2 \\
\hline Average number of $\mathrm{m}$ & Average number of messages & 10.5 & 7.5 \\
\hline
\end{tabular}

\section{DISCUSSION}

The significant difference between African American and Caucasian students, asking questions in the second and third messages, should not be overlooked. The findings show that African Americans asked more questions in their second and third messages when compared to Caucasian students.16 The transactions that were sent by African Americans included more messages (average number of messages per transaction was 10.5) than those sent by Caucasians (average number of messages per transaction was 7.5). The findings are consistent with previous studies reporting that African Americans spent more time per week in the library than Caucasians.17 While the number of messages was not statistically different in our study, the number of questions in the transactions was larger for the African American students compared with the Caucasian students. In particular African Americans were asking more questions in the second and third messages (almost twice as many in the second message and more than four times as many requests in the third message). It is possible that these differences illustrate a deeper gap between the two user groups. For example, while Caucasian students were more likely than African Americans to ask for help initially, for whatever reason, once an African American student had made the initial request, it is more likely that other information needs will be sent to the reference librarian. Is it that African Americans have greater challenges in using remote reference services? Is it that they have greater information needs that should be 
addressed? Or, is it that they are more satisfied than their Caucasian peers with the remote reference service?18 If so, does it mean that their expectations of the service are lower to begin with? It is possible that African Americans, who have historically faced racial discrimination, may be more likely to "test the waters" with their first question to see what kind of reception they will receive. We also found that African Americans tend to include excessive gratitude in their messages more than did their Caucasians peers (10 percent of African American and only 2 percent of Caucasian, though these were included rarely in messages of either group).

Table 2 Difference Between African American and Caucasian

\begin{tabular}{llcccc}
\hline Variable $^{\mathrm{a}}$ & & Pearson $\chi 2$ & Cramer's $V$ & $>P$ value & $>$ Significance \\
\hline Type of question & Topical & 2.54 & .165 & .1 & $*$ \\
& Known item & 2.01 & .146 & .1 & $*$ \\
& Technical & 5.3 & .238 & .02 & $* *$ \\
Style & Non-reference & .07 & .02 & .77 & - \\
& Medium & .49 & .06 & .48 & - \\
& Greetings & .17 & .04 & .67 & - \\
& Closure & .89 & .09 & .34 & - \\
& Elaborate & .25 & .05 & .61 & - \\
& Exact & .04 & .02 & .82 & - \\
& Succinct & .00 & .00 & 1 & - \\
& Context irrelevant & .38 & .06 & .53 & - \\
& Purpose & .07 & .02 & .78 & - \\
& Search history & .1 & .03 & .74 & - \\
& Typos & .04 & .02 & .82 & - \\
& Grammatical & 3.2 & .18 & .07 & $*$ \\
Number of questions & Second & 5.5 & .24 & .01 & $* * *$ \\
\hline
\end{tabular}

$\mathrm{N}=94, \mathrm{df}=1$.

*Significance $<.1 * *$ Significance $<.05 * * *$ Significance $<.01$.

${ }^{a}$ Only variables with at least five cases per cell in the contingency table are included in this table.

Finally, significant differences were found in the type of requests that were sent by African American and Caucasian students. African American students asked almost twice as many topical questions and more known-item questions, but significantly fewer technical questions than Caucasian students. These differences are in alignment with the fact that African Americans asked more reference requests in the second and third message. Thus, these findings indicate that African Americans may need more library support (topical and known item requests) than their Caucasian peers. In addition, the difference in technical requests could be explained in several ways. First, as previously suggested, it is possible that Caucasian students have fewer technical limitations in accessing the reference desk, when compared to African Americans. However, those African Americans who asked questions using e-mail are more technologically savvy, and therefore need less help with technical requests. This hypothetical explanation should be further investigated in future studies. 
While some differences were found between the two user groups they were found to be mostly similar. It should be emphasized that the style of the requests did not differ between the two user groups. They used greetings, closure, apologies, shared the purpose of their information needs with the librarian, and provided irrelevant information in the message as frequently. The frequency of misspelling and typos was similar in the requests of the two groups.

\section{CONCLUSION}

Today more than ever, minority, non-traditional, and international students are attending American colleges. These diverse student populations are making growing use of library services, including virtual reference services. They are facing additional challenges compared to traditional students in these higher education institutions, yet little had been done to gain a better understanding of the user needs, information seeking behavior and usage of library services in the virtual context. This study examined the similarities and differences in information needs and the use of virtual reference services between African American and Caucasian students and shed some light on this knowledge gap.

Once African American students ask a question, they are more likely to ask second and third questions compared with Caucasian students. African American students asked more topical and known-item questions and fewer technical questions than Caucasian students. In addition, reference transactions of African Americans consisted of more messages and they tend to use excessive gratitude more frequently than Caucasian student. However, African American and Caucasian students used similar style in their messages. Both groups used greetings, closure, and apologies similarly. They have used mostly the exact writing style. They shared the purpose of their information needs with the librarian at the same frequency and provided irrelevant information in the message as often. They also had a similar amount of misspelling and typos. Further research should try to understand why these differences in usage patterns have been found.

Differences in academic achievements between these two groups are well documented in the literature and a better understanding of their library use is still needed. This study adds to our understanding of cultural differences in information-seeking behavior and library use and in particular it focuses on differences and similarities in the use of virtual reference service. Gaining a better understanding of the differences and similarities between diverse user groups will help librarians address the needs of these diverse user populations. It also has the potential to improve library services to these user groups, and consequently to improve their academic achievement. The first step is to conduct more studies of minorities and non-traditional students' information needs and user behaviors. 
APPENDIX A: CODING SCHEME

\begin{tabular}{|c|c|c|}
\hline & Code Name & Definition \\
\hline \multirow[t]{9}{*}{$\overline{\text { Style }}$} & Greetings & $\begin{array}{l}\text { The student included "Hello",'Dear”, or some } \\
\text { equivalent before the content of the message }\end{array}$ \\
\hline & Closure & $\begin{array}{l}\text { The student included a "thank you" or "sincerely" } \\
\text { or some equivalent before concluding the message }\end{array}$ \\
\hline & Elaborate & The student's message was very wordy \\
\hline & Exact & $\begin{array}{l}\text { The student provide relevant and sufficient } \\
\text { information }\end{array}$ \\
\hline & Succinct & The student did not provide enough information \\
\hline & Context-irrelevant & $\begin{array}{l}\text { The student provided extra, irrelevant information } \\
\text { that was not necessary }\end{array}$ \\
\hline & Purpose & $\begin{array}{l}\text { The student said why they were looking for the } \\
\text { information }\end{array}$ \\
\hline & Misspelled & $\begin{array}{l}\text { The student had at least one misspelling that did not } \\
\text { look like a typo }\end{array}$ \\
\hline & Typos & $\begin{array}{l}\text { The student had at least one typo that did not look } \\
\text { like a misspelling }\end{array}$ \\
\hline \multirow[t]{3}{*}{ Style } & Grammatical & $\begin{array}{l}\text { The student had at least one significant grammatical } \\
\text { error }\end{array}$ \\
\hline & Apologies & $\begin{array}{l}\text { The student apologized for bothering the library or } \\
\text { for taking too long to respond to the library’s last } \\
\text { message }\end{array}$ \\
\hline & Excessive gratitude & $\begin{array}{l}\text { The student provided gratitude beyond a simple } \\
\text { "thank you" }\end{array}$ \\
\hline \multirow[t]{7}{*}{ Type of question } & Topical & The question asked was a topical question \\
\hline & Known item & $\begin{array}{l}\text { The student was looking for the full text of a book } \\
\text { or article they have already identified }\end{array}$ \\
\hline & Technical & $\begin{array}{l}\text { The student needed computer assistance or help } \\
\text { getting into the databases }\end{array}$ \\
\hline & Searching instruction & $\begin{array}{l}\text { The student needed instruction on using the } \\
\text { databases }\end{array}$ \\
\hline & Citation & $\begin{array}{l}\text { The student was requesting information on how to } \\
\text { Cite materials in their papers }\end{array}$ \\
\hline & Verification & $\begin{array}{l}\text { The student was asking for assistance verifying a } \\
\text { citation or other information }\end{array}$ \\
\hline & Non-reference & These included queries about library policy \\
\hline
\end{tabular}




\section{NOTES AND REFERENCES}

1. US Census Bureau. United States population and housing narrative profile, 2004 data set: American Community Survey. (2004). Retrieved January 28, 2006 from http://factfinder.census.gov/servlet/NPTable?_bm=y\&-geo_id=01000US\&gr_name=ACS_2004_EST_G00_NP01\&-ds_name=\&-redoLog=false.

2. Pew Internet \& American Life Project. Latest trends: Who is online. (2005). Retrieved January 28, 2006 from http://www.pewinternet.org/trends/User_Demo_12.05.05.htm.

3. Based on the 2005 National Center on Educational Statistics Table 254 (available at http://nces.ed.gov/programs/digest/d05/tables/dt05_205.asp) while in 1975 only 14.5 percent of the students were of a minority group, by 1980 it was 19.6 percent, and by 200430.4 percent of the total fall enrollment in degree-granting institutions was minorities.

4. Qun G. Jieo, Anthony J. Onswuengbuzie, and Sharon L. Bostick, "The Relationship Between Race and Library Anxiety Among Graduate Students: A Replication Study,’’ Information Processing and Management 42 (2006): 843-851

5. Ethelene Whitmire, “A Longitudinal Study of Undergraduates,” Academic Library Experiences, The Journal of Academic Librarianship 27 (5) (2001): 379-385.

6. Anthony Biglan, "The Characteristics of Subject Matter in Different Academic Areas," Journal of Applied Psychology 57(1973a): 195-203; Anthony Biglan, “'Relationship Between Subject Matter Characteristics and the Structure and Output of University Departments,' Journal of Applied Psychology 57(1973b): 204-213; Tracy A. Burdick, "Success and Diversity in Information Seeking: Gender and the Information Search Styles Model,' School Library Media Quarterly (Fall 1996): 19-26; Lois Buttler, "Facilitating Cultural Diversity in College and University Libraries,'” The Journal of Academic Librarianship (March 1994): 10-13; Mengxiong Liu and Bernice Redfern, 'Information Seeking Behavior of Multicultural Students: A Case Study at San Jose State University,’’ College \& Research Libraries 58 (4) (1997): 348-354; Cathrine S. Ross, Kirsti Nilsen and Patricia Dewdney, "Interviewing Adults with Special Language-Related Needs.” in: Conducting the Reference Interview (New York: Neal-Schuman Publishers, 2002), 152-156; Linda C. Ueltschy, Michel Laroche, Robert D. Tamilia and Peter Yannopoulos, "Cross-Cultural Invariance of Measures of Satisfaction and Service Quality,’ Journal of Business Research 57 (12) (2004): 901-912; Barbara Valentine, ' 'Undergraduate Research Behavior: Using Focus Groups to Generate Theory,'” The Journal of Academic Librarianship 19 (1993): 300-304; Whitmire, “A Longitudinal Study,” 2001; Ethelene Whitmire, “'Disciplinary Differences and Undergraduates’ Information-Seeking Behavior,' Journal of the American Society for Information Science and Technology 53 (8) (2002): 631-638; Ethelene Whitmire, “'Cultural diversity and Undergraduates' Academic Library Use,” The Journal of Academic Librarianship 29 (3) (2003): 148-161; Lucinda R. Zoe and Diane DiMartino, "Cultural Diversity and End-User Searching: An Analysis by Gender and Language Background,’ Research Strategies 17 (2000): 291-305.

7. Zoe and DiMartino, "Cultural Diversity and End-User Searching."'

8. Jiao et al. p. 844.

9. Stacy-Bates Katherine, “E-mail Reference Responses from Academic ARL Libraries: An Unobtrusive Study,’’ Reference and User Services Quarterly 43 (1) (2003): 59-70.

10. Steve Coffman, “Going Live: Starting and Running a Virtual Reference Service.’ American Library Association: Chicago (2003); Joe Janes, “'Digital reference: Reference librarians’ experiences and attitudes.' Journal of the American Society for Information Science and Technology 53(7) (2002): 549-566. 
11. Coffman, "Going Live."

12. Lara Bushallow-Wilbur, Gemma DeVinney, and Fritz Whitcomb, "Electronic Mail Reference Service: A Study,” Reference Quarterly 35 (3) (1996): 359-371 Stacy-Bates, “Email Reference Responses.'”

13. Stephen H. Dew, “'Documenting Priorities, Progress, and Potential: Planning Library Services for Distance Education,” Journal of Library Administration 37(1/2) (2002): 217241; Zheng Ye Yang. "Distance Education Librarians in the U.S. ARL Libraries and Library Services Provided to their Distance Users,” The Journal of Academic Librarianship 31(2) (2005): 92-97.

14. These terms were used by the university.

15. Explain in detail what constitutes a transaction.

16. It should probably be clarified here again that a transaction included several interactions among the user and the service providers by phone and e-mail over a period of time. Thus, each transaction may include a few instances of requests that represent user information needs.

17. Grimes and Charters, "Library Use."

18. "Willingness to return" and ask another question was found to be an indication of user satisfaction from the reference service and is an indication of the quality of reference services as suggested by Joan C. Durrance, "Reference Success: Does the 55\% Rule Tell the Whole Story?” Library Journal 1989: 31-36; Joan C. Durrance, “Factors that Influence Reference Success: What Makes Questioners Willing to Return?’’ The Reference Librarian 49/50 (1995): 243-265; Patricia Dewdney and Ross Catherine, "Flying a Light Aircraft: Reference Service Evaluation from a User’s Viewpoint,’’ Reference Quarterly 34(2) (1994): 217-230. 